\title{
O DISCURSO DOS TELEJORNAIS DA REDE PÚBLICA E PRIVADA DE MOÇAMBIQUE: Jornal Nacional e Jornal da Noite ${ }^{1}$
}

\author{
The speech from the television news of the public and private network of \\ Mozambique: Jornal Nacional and Jornal da Noite
}

Leonilda Adelino António Sanveca Muatiacale ${ }^{2}$

\section{Resumo}

A partir do pressuposto de que existe uma promiscuidade na relação entre o telejornalismo e o poder político em Moçambique, o artigo discute como ela se manifesta no discurso dos telejornais: Jornal Nacional e Jornal da Noite, da rede pública e privada. O telejornal é um espaço midiático em que os textos produzidos se vinculam a determinados discursos cuja finalidade é criar efeitos de sentido. É nesse prisma que este artigo disseca a noção de discurso, do ponto de vista da capacidade persuasiva e da sua relação intrínseca com os conceitos de ideologia e hegemonia que influenciam as relações dos agentes do discurso que, muitas vezes, tornam-se reprodutoras de estruturas de poder.

Palavras-chave: Televisão; Telejornalismo; Discurso; Moçambique.

\section{Abstract}

The article discusses the relation between the television speeches of Jornal Nacional and Jornal da Noite, public and private network, considering that there is promiscuity in the relation between news programmes and the political power in Mozambique. Television is a mediatic space in which produced texts scatter themselves at determined speeches which aim to produce meaningful effects. Under these circunstances, the article dissects the notion of discourse, from the point of view of its persuasive capacity and its intrinsic relationship with the ideological concepts and supremacy that influence the relationship of agents of discourse that, many times, become multipliers of power structures.

Keywords: Television; News programmes; Speech; Mozambique.

Este tema faz parte da dissertação defendida na PUC-SP, em dezembro de 2007.

2 Mestre em Comunicação e Semiótica pela Pontifícia Universidade Católica de São Paulo. e-mail: leosanveca@yahoo.com.br 


\section{Introdução}

A proposta é discutir, neste artigo, a noção de discurso e suas condições de emergência nos telejornais da rede pública e privada de Moçambique, levando em consideração os poucos anos de história da televisão no país. Nesse contexto, importa questionar que estratégias discursivas são construídas e mobilizadas pelos telejornais do horário nobre: Jornal Nacional da Televisão de Moçambique (TVM) - emissora pública e Jornal da Noite da Soico Televisão (STV) - emissora privada para estabelecer contrato midiático com seu telespectador.

O conceito de contrato fiduciário, também denominado contrato midiático ou de comunicação, é entendido aqui, em sua acepção mais ampla, nos termos da semiótica greimasiana, como a relação de confiança e confidência que se estabelece sutilmente entre enunciador-enunciatário, enquanto protagonistas do discurso. Tais condições de interação abarcam todo o conjunto de jogo de negociações implícitas que fazem com que o enunciatário acredite e confie no discurso do enunciador como verdadeiro e, por isso, digno de confiança.

Para essa discussão, salientamos a necessidade de se levar em consideração a diversidade cultural, étnica e lingüística da população. No censo de 1980 , de acordo com Mazula (1995, p. 123), "foram identificados dezesseis grupos étnicos e vinte e quatro línguas nacionais". O autor revela também que para a maioria da população, as línguas maternas são as mais utilizadas na comunicação cotidiana. Ademais, os elevados índices de analfabetismo, em torno de $53,6 \%$ dos cerca de vinte milhões de habitantes, de acordo com dados do Instituto Nacional de Estatísticas de Moçambique (INE), afiguram-se também como maiores dificuldades na compreensão do discurso dos telejornais.

Nesse sentido, discutir a noção de discurso assim como os conceitos de ideologia e hegemonia, no âmbito do telejornalismo moçambicano, implica considerar também o contexto histórico, político, econômico e sociocultural em que o discurso emerge e se manifesta por meio de seus textos. É nesse prisma que buscamos dissecar a noção de discurso, do ponto de vista de sua capacidade persuasiva e da sua relação intrínseca com a ideologia e a hegemonia que influenciam as relações dos agentes do discurso que, muitas vezes, tornam-se reprodutoras de estruturas de poder. Como é que o poder político influencia o discurso dos telejornais? Quais as formas de figuratividade do governo que os telejornais apresentam em seus textos?

O principal argumento é de que o telejornal é um espaço midiático da atualidade em que os textos produzidos se vinculam a determinados discursos que possibilitam a construção de efeitos de sentido. Servindo-se de procedimentos discursivos, os enunciadores mobilizam suas estratégias persuasivas para convencer seus enunciatários.

Nesta incursão, nos ancoramos no arcabouço teórico das Teorias do Discurso de Laclau e Mouffe (1985) e de Norman Fairclough (2001), que defendem a tese de que o discurso deve ser compreendido em seu contexto social, porque o significado de qualquer texto não reside apenas no que o enunciador profere $\mathrm{e}$ nem só na percepção do enunciatário, mas na relação que se estabelece entre essas instâncias da enunciação e do contexto em que estão inseridas.

Os postulados de Fairclough e Laclau oferecem-nos um vasto escopo de aplicação para esse estudo porque compreendemos que as Teorias de Discurso procuram estabelecer um quadro analítico capaz de mapear a conexão entre relações de poder e recursos lingǘsticos selecionados por pessoas ou grupos sociais com determinados objetivos.

Esses fundamentos nos ajudam a compreender com clareza o conceito de discurso e suas implicações no contexto em que é construído e difundido, nesse caso, nos telejornais Jornal Nacional e Jornal da Noite.

Consideramos como hipótese principal a existência de uma relação promíscua entre o governo e as emissoras de televisão, sobretudo a pública que, desde a independência até a atualidade, trabalha sob o controle do governo, embora a constituição do país garanta a liberdade de expressão e de imprensa. Outra hipótese que norteia a discussão é o fato de que a maneira de informar dos telejornais legitima o poder político por meio da valorização da dimensão passional do sentido, que organiza processos afetivos e leva o telespectador a aceitar o discurso do telejornal como verdadeiro por causa da sua identificação histórica, social, política e com a emissora.

\section{A televisão em Moçambique}

Para compreendermos a evolução da televisão em Moçambique e sua relação com o poder político, é fundamental passarmos por uma breve 
análise histórica da imprensa, no sentido mais amplo (rádios, jornais e revistas), pelo fato de seguir a mesma trajetória política do país.

Nessa trajetória histórica dos meios de comunicação, distinguem-se quatro etapas principais. A primeira, em que se estabeleceram jornais impressos e uma rádio nacional, que serviam aos interesses da metrópole (Portugal); a segunda, compreende a época do surgimento da imprensa de combate criada pelos moçambicanos, cuja função era contestar a presença colonial no território moçambicano; a terceira é a da imprensa no período pós-independência, usada pelo governo para a mobilização das massas. Nesse período, Leite Vasconcelos (apud RIBEIRO, 1996, p. 142) revela que "os órgãos de informação deviam informar, educar e mobilizar o povo para o combate à miséria, à ignorância, ao subdesenvolvimento, ao tribalismo e ao racismo"; a quarta etapa constitui o período dos anos 90 até a atualidade, que é marcada pela ampliação do mercado dos meios de comunicação no âmbito nacional e pela entrada de novas emissoras privadas de televisão.

Neste ensaio, destacamos o período pósindependência marcado pela criação da Televisão em 1981, além da década de 90, pelas grandes mudanças ocorridas no cenário mundial e no contexto nacional, pela promulgação da primeira Constituição da República de cunho democrático em 1990. Nesse sentido, Chambote (2006, p. 25) explica que algumas das alterações de realce nesta constituição podem ser vistas: quanto ao sistema político; à ideologia; à área de intervenção econômica; à esfera dos direitos individuais e sua garantia; aos órgãos do Estado; garantias e revisão constitucional; e relacionamento internacional. Vale lembrar que antes dessa fase, a ideologia do partido no poder era de inspiração marxista-leninista.

Desde a independência até essa época, em Moçambique, a mídia era monopólio do Estado, sob o comando do partido único no poder, a Frelimo (Frente de Libertação de Moçambique), que controlava todo fluxo de informações e definia as políticas editoriais dos poucos veículos disponíveis por meio do Ministério da Informação.

Essa interferência do governo na mídia não é problema recente e tão pouco só de Moçambique. $\mathrm{Na}$ década de 80, no Brasil, Melo (1979, p. 9) constatou que tanto na estrutura capitalista quanto na sociedade socialista, os meios de comunicação de massa estão sob domínio da elite dirigente. Para o autor, no primeiro caso, pertencem aos grupos econômicos que exploram como organizações industriais, produtoras de bens de consumo. No segundo, estão sob a influência do Estado, o que corresponde a dizer que se encontram nas mãos da elite política que detém o poder.

O caso de Moçambique enquadra-se perfeitamente em ambos os modelos porque os veículos públicos de comunicação de massa estão sob o domínio e controle do poder político, enquanto os do setor privado pertencem a empresas dedicadas ao ramo das telecomunicações que se formaram a partir da década de noventa.

$\mathrm{Na}$ opinião de Miguel (2003, p. 10), o fenômeno televisivo moçambicano, a partir do momento em que foi adotada a economia de mercado e publicada a Lei da Imprensa n. 18/91 de 10 de agosto, incorporou-se à dinâmica do capitalismo contemporâneo. O empresariado nacional, formado em boa parte pelos membros do grupo governista e o empresariado transnacional passaram a utilizar esse meio de comunicação como alavanca de rentabilização de seus negócios.

Hoje, com a entrada de veículos de comunicação do setor privado, sobretudo da televisão, aumentou a disputa pela audiência, o que implica em mudanças nas estratégias discursivas utilizadas por cada emissora para garantir audiência. É nesse sentido que se torna oportuno refletir sobre o conceito de discurso e suas implicações no contexto social.

\section{O conceito de discurso}

A noção de discurso é de uma complexidade teórica e social muito ampla. Em seus postulados, Fairclough (2001), em "Discurso e mudança social", e Laclau (1985), nas suas Teorias do Discurso, em Hegemony \& Socialist Strategy: towards a radical democratic politics, referem que o discurso só pode ser compreendido em seu contexto de emergência.

Constatamos que embora a conceituação de discurso desses autores tenha partido de áreas diferentes (Política e Lingüística), os seus postulados têm alguns aspectos comuns que podem nos ajudar na compreensão dos fenômenos comunicacionais da sociedade contemporânea e concretamente em Moçambique.

Fairclough (2001, p. 90) usa o termo "discurso" para se referir "ao uso de linguagens, como forma de prática social e não como atividade puramente 
individual ou reflexo de variáveis situacionais". Na visão do autor, essa concepção de discurso pode trazer várias implicações. A primeira é o fato de "ser o discurso um modo de ação, uma forma em que as pessoas podem agir sobre o mundo e especialmente sobre os outros, como também um modo de representação". Nesse sentido, se olharmos a conjuntura moçambicana, perceberemos que embora os objetivos de ambos os telejornais passem pelo aumento de audiência, a tônica do seu discurso é diferente.

Para compreendermos as possíveis razões dessa diferença, recorremos a Bolaño (2004), que aponta a existência de uma lógica ideológica e outra comercial. Com base nesse pensamento, observamos que as estratégias discursivas do Jornal Nacional revelam sua tendência em privilegiar o discurso do poder político. Ao construir representações figurativas apresentando o governo como bom, como salvador da pátria, como construtor de uma nação mais coesa apesar da diversidade étnicolingüística, como libertador do povo da dominação colonial, o Jornal Nacional atua com uma lógica ideológica e simbólica.

De fato, no telejornal, a ideologia nem sempre está na externalização do fenômeno, ou seja, na explicitação do que se fala. Embora exista uma vasta literatura que versa sobre o conceito de ideologia, neste artigo, assumimos a concepção de Thompson (1998, p. 79), do significado de ideologia como sendo a maneira como o sentido é mobilizado a serviço dos indivíduos e grupos dominantes, isto é, as maneiras como o sentido é construído e transmitido pelas formas simbólicas e serve, em circunstâncias particulares, para estabelecer e sustentar relações estruturadas das quais alguns indivíduos se beneficiam mais que outros.

Thompson (1998, p. 79) designa de "formas simbólicas" a um amplo espectro de textos ${ }^{3}$ que produzam efeitos de sentido. Vista desse ângulo, a ideologia pode estar localizada na aparente objetividade de um determinado discurso, no jogo de interpretações nele subjacentes que podem servir aos mais variados interesses, ou na omissão de informações que possam abrir horizontes mais amplos para o público telespectador.
Com esses elementos teóricos sobre o conceito de ideologia e seu delineamento em Thompson e da observação crítica dos telejornais, podemos auferir com segurança que o discurso do Jornal Nacional é marcado, entre outros aspectos, por reiterações óbvias sobre as realizações do governo. Isso tem objetivos de supervalorizar esses feitos do governo, além de presentificar constantemente a autoridade para que seja o centro das atenções do telespectador.

O Jornal Nacional recorre ao uso de linguagem que busca produzir efeitos de sentido de consenso que pode levar à aceitação do governo como legítimo. Essa característica revela também o engajamento da emissora na promoção do marketing político do governo e da propagação da ideologia do partido no poder. A função desse tipo de estratégias discursivas e dessa lógica simbólica e ideológica é desencadear mecanismos de identificação do telespectador com o discurso do telejornal e, com isso, levá-lo a reconhecer, aceitar e legitimar o poder político instituído sem quaisquer contestações.

Em contrapartida, as estratégias discursivas do Jornal da Noite revelam uma lógica comercial e o quanto a emissora se preocupa em mostrar a diversidade de opinião perante os fatos noticiados na tentativa de buscar credibilidade e consistência em seu discurso diante do telespectador. Essas estratégias procuram garantir audiência, na possibilidade óbvia de derrubar o forte concorrente, o Jornal Nacional.

Os postulados de Fairclough, assim como os de Laclau, constituem um quadro ilustrativo do modo como os discursos podem apresentar-se no contexto social e como eles (os discursos) afetam os telejornais e vice-versa, na atualidade.

A perspectiva explorada nessa pesquisa tem a ver com o que Laclau revela pelo fato de no telejornal também emergir a pluralidade de discursos que se manifestam, se entrecruzam e/ou se imbricam e, muitas vezes, entram em conflito com o discurso político hegemônico. Por isso, faz sentido a tese de Oliveira (1998, p. 157) de que o como um dado telejornal se dá a ver é um modo de se posicionar

3 O termo texto refere-se à totalidade de uma cadeia lingüística, ilimitada em decorrência da produtividade do sistema. É qualquer totalidade de sentido. Em outras palavras, é a unidade mínima da Semiótica Discursiva. GREIMAS, A. J.; COURTÉS, J. Dicionário de semiótica. Tradução de Alceu Dias Lima et al. São Paulo: Cultrex, 1979. p. 460. 
no mundo, de assumir um sistema de valores para transformá-lo ou negá-lo. Para a autora, "os valores incorporam, pois, o discurso antes das distinções entre temas ou gêneros. Dessa forma é antes de tudo, o fazer televisão, isto é, informação em televisão, que traz em si uma afirmação política".

Com base nessas asserções, é possível afirmar que, do ponto de vista institucional, no telejornalismo, são inevitáveis os conflitos decorrentes de posicionamentos ideológicos no interior das emissoras e conseqüentemente nos discursos que as perpassam.

Mas a questão da dependência e submissão da televisão e, em particular, do telejornal em relação ao poder político, em Moçambique ou em qualquer outro país, remonta à Teoria Funcionalista, cuja abordagem defende que as funções dos meios de comunicação de massa se centram na manutenção do status quo e do equilíbrio na sociedade.

De acordo com Wolf (2003, p. 67), "independentemente da sua ordem institucionalorganizacional, outra função da mídia é atribuir status e prestígio às pessoas e aos grupos transformados em objeto de sua atenção". Para Wolf, determina-se um esquema circular do prestígio para o qual esta função, que consiste em conferir um status, entra na atividade social organizada, legitimando certas pessoas, grupos e tendências selecionados que recebem o apoio dos meios de comunicação de massa.

Faz-se necessária uma visão crítica sobre o discurso dos telejornais pelo paradoxo que sua atividade envolve porque apesar de seu caráter informativo e/ou opinativo, os telejornais também refletem, de alguma forma, o jogo de interesses políticos e mercadológicos que se configuram na relação entre a Comunicação e o Estado enquanto instituições. Por isso, trata-se, portanto, de se retirar qualquer aura ingênua de que possam aparentemente se revestir.

Aliás, em suas teses, Eugênio Trivinho (2001, p. 70) chama essa relação promíscua entre Comunicação e Estado de "sombra do Estado: duplicação social-histórica de funções institucionais" e revela que, "a forte impressão que a comunicação cria é justamente a de que, no transcurso do pósguerra, a vida foi, pari passu, se deslocando, é certo que não totalmente, mas em ampla medida, da instituição Estado para a instituição Comunicação".
Para Trivinho (2001, p. 70), não se trata propriamente de um deslocamento de funções; o que era do Estado permanece com o Estado. Tratase, antes, de uma duplicação social-histórica de expedientes que até bem pouco tempo competiam somente ao Estado realizar, em virtude de, para isso, ele tributar amplamente a sociedade.

As asserções de Trivinho (2001) confirmam o que acontece com os telejornais moçambicanos que estão encurralados pelas regras impostas pelo governo, por isso, são claras as contradições do discurso de ambos os telejornais, sobretudo da emissora pública, cujos inúmeros problemas se agravam com a falta de liberdade de expressão, na prática, porque pela lei ela é garantida, por meio do artigo 74 da Constituição da República de 1990.

Nota-se essa falta de liberdade dos profissionais pela ausência de questionamentos, de debates críticos em relação ao poder político. A emissora pública limita-se apenas à exaltação das realizações do elenco governamental e ao silenciamento das atividades de outras formações políticas que constituem a oposição, e até mesmo da sociedade civil que não são amplamente divulgadas de igual forma que as do governo.

Esse comportamento da emissora pública tem recebido críticas de alguns pesquisadores da comunicação que se dedicam ao estudo das atuações da imprensa em Moçambique. Destacam-se as contribuições de Miguel (2003), de Vasconcelos apud Ribeiro (1996) e de Celestino Vaz Tomás, no relatório do MISA ${ }^{4}$ (2005). Nesse documento, Tomás sustenta que um dos traços que denuncia a cumplicidade da TVM e o poder político instituído foi o fato de que nas últimas eleições presidenciais e legislativas, embora a Lei permita o Direito de Antena para os demais partidos políticos, o silêncio da TVM em relação às atividades políticas dos partidos políticos de pouca expressão era a chave de ouro.

Para compreendermos essa relação no campo dos discursos, Fairclough (2001, p. 94) explica que "o discurso como prática ideológica constitui, naturaliza, mantém e transforma os significados do mundo em posições diversas nas relações de poder". Para Fairclough, "os aparelhos ideológicos de Estado (instituições tais como a educação e a mídia) são ambos locais e delimitadores na luta de classe, que apontam para a luta no discurso".

4 MISA é o Instituto de Comunicação da África Austral também presente em Moçambique. Esse órgão divulga anualmente um relatório sobre o estado da liberdade de imprensa no país. 
A tese de Fairclough de que o discurso pode ter orientação ideológica é compactuada por Thompson (1998, p. 16), para quem "ideologia, falando de uma maneira mais ampla, é sentido a serviço do poder" (grifo do autor). É nessa esfera teórica conceitual que as estratégias discursivas e fiduciárias dos dois telejornais devem ser vistas e discutidas para se compreender como suas produções diárias possibilitam o compartilhamento de sentido capaz de interligar os sujeitos sociais no imaginário comum, por congregar diversos grupos étnicos, sociais e políticos a pensarem sobre os mesmos problemas em vista a suscitar mudanças significativas no ambiente democrático de Moçambique, enquanto Estado-nação.

Com base em características específicas desse formato televisual que envolve diversas vozes e sujeitos que intervêm em seus discursos, não se tem dúvida de que os telejornais realizam a função de espaço público, enquanto lugar de debate sobre assuntos do cotidiano do país, independentemente da natureza pública ou privada de cada emissora.

Deve-se reconhecer também que, enquanto atividade que reúne e edita as notícias, o telejornalismo pode oferecer um quadro tendencioso sobre os acontecimentos, por isso, Traquina (2003), Machado (2003), Wolf (2003), Becker (2005) e outros autores críticos da comunicação sugerem, em seus estudos, a necessidade de um conhecimento maior do telejornalismo e de suas influências na sociedade para sabermos como nos posicionar diante de suas versões nos noticiários exibidos diariamente.

Se considerarmos o telejornal como o locus privilegiado das interações argumentativas contemporâneas, percebemos que as idéias defendidas pela dupla pós-marxista Laclau e Mouffe, nas suas discussões sobre a emergência dos discursos no contexto histórico do marxismo, são problemas que também se inscrevem no cenário moçambicano.

Nessa lógica de idéias, Lipovetsky (2005, p. 262) afirma que "não chegamos ao fim das ideologias, mas à configuração de um outro tipo de ideologia, a ideologia-moda, orientada pela autonomia, pelo hedonismo, pelo psicologismo, o que torna possível o rodízio leve do sentido".

É nesse contexto de emergência de novos discursos que se pode fazer uma releitura da realidade moçambicana após a independência, período em que o novo governo se tornou neófito no marxismo e impôs a ideologia marxista-leninista por meio de seu partido. De acordo com Mazula
(1995), nessa época, já era possível detectar o que a nova política da Frelimo aspirava derrubar, a todo custo, o sistema tribal tradicional em nome da modernidade, da unidade nacional e da construção do "Homem Novo".

Para levar adiante esse projeto, com fortes traços do iluminismo, o partido utilizou a imprensa e, mais tarde, a televisão, como veículos mais qualificados para a propagação de seus ideais nacionalistas. Nesse sentido, as asserções de Saúte apud Ribeiro (1996, p. 158) mostram como a urgência de construir uma pátria convocou a imprensa em volta da utopia que serviu como bandeira das proclamadas e lídimas aspirações do povo.

Saúte refere que a Frelimo, usando estrategicamente essa adesão à causa libertadora, empregou todos os artifícios para construir o seu regime, inspirado nos modelos que importara do Leste. A imprensa, a rádio e, posteriormente, a televisão, foram instrumentos privilegiados para tornar eficaz a propaganda dos valores prezados pelo regime.

Com essa postura já era visível a relação ambígua dos meios de comunicação de massa com o poder político que, na década de 80 , acirrou-se ainda mais com a entrada da televisão. Esse veículo veio a ser o espaço privilegiado do governo para se mostrar ao público. Aliás, Lipovetsky (2005) oferecenos algumas contribuições sobre essa necessidade de superexposição do poder político na mídia. $\mathrm{O}$ autor designa de cena política o cenário em que os políticos comparecem para propalar suas idéias e ocupar o centro dos noticiários, sobretudo televisivos, no intuito de serem vistos e reconhecidos como bons governantes e salvadores da pátria.

É nesse ambiente de uma ideologia que instaurava de forma autoritária e monolítica a prática política que o jornalismo moçambicano era exercido e, quando em 1981 foi criada a então Televisão Experimental de Moçambique (TVE), a primeira emissora de televisão no país, seguiu a mesma dinâmica. Durante cerca de vinte anos, só ela "reinou" sob os auspícios do governo sem nenhuma concorrência.

Com a criação de outras emissoras do setor privado, como a TV Miramar, em 1998, e a STV, em 2002, além de outras criadas posteriormente, a Televisão pública viu-se desafiada, e conseqüentemente também o partido no poder, pela iminente possibilidade de perder seu lugar privilegiado de único partido emissor do discurso. 
Aliás, o cenário já mostra algumas mudanças significativas. Loforte in Misa (2005, p. 73) afirma que "quanto à Televisão de Moçambique, não restam dúvidas de que ela sofreu, em 2005, uma acentuada baixa de níveis de audiência e um descrédito quase generalizado dos seus conteúdos informativos". Em contrapartida, percebe-se ainda a persistência de certo desequilíbrio, pois o espaço da Frelimo na TVM continua maior que o das outras formações políticas, o que lhe confere certa hegemonia no discurso político-ideológico.

É possível compreender essa tendência à luz dos postulados de Fairclough (2001, p. 92) que reafirma que "a constituição discursiva da sociedade não emana de um livre jogo de idéias nas cabeças das pessoas, mas de uma prática social que está firmemente enraizada em estruturas sociais materiais, concretas, orientando-se para elas". Portanto, sabe-se que a Frelimo possui fortes raízes na estrutura social moçambicana, cujo enfraquecimento vai levar muito tempo. Ademais, também é reconhecido o seu discurso mobilizador das massas, desde o processo de independência seguido de todo o processo de inculcação de valores considerados, por esse partido, comuns ao povo moçambicano.

É com base nesse contexto sociopolítico, histórico e econômico e nas características específicas desse formato televisual que consideramos o telejornal como espaço semiótico de manifestação dos discursos fortemente marcado pela hibridação de linguagens que buscam dar conta da nova realidade da configuração social em Moçambique.

Com isso, abre-se um campo de disputas inerentes à necessidade de legitimação das esferas produtoras de discurso que passa pela sua articulação para que tenha sentido, ou melhor, que produza efeitos de sentido. Essa articulação discursiva é possível graças à inter-relação entre discurso, ideologia e hegemonia.

\section{A tríplice relação entre discurso- ideologia-begemonia}

Para entendermos a magnitude do conceito de discurso devemos voltar nossa atenção para a sua relação com outros conceitos, como ideologia e hegemonia, pois estão intimamente interligados, além de considerarmos também o espaço, enquanto Estadonação, em que essas dimensões conceituais são vividas.
Nesse sentido, percebemos que em Moçambique, o canal público tem se deixado moldar pelo partido no poder que articula e explora melhor essa relação triádica: discurso-ideologia-hegemonia, sempre a seu favor, utilizando-se dos meios de comunicação como instrumentos de veiculação de sua ideologia.

Como já nos referimos, o país aderiu à democracia em 1990, com a adoção de uma nova Constituição da República, que abriu espaço para o sistema político multipartidário. O cessar fogo e a posterior assinatura do Acordo Geral de Paz em 1992 foram aspectos que marcaram o fim da guerra civil que envolvia o governo e a oposição. Mas, a partir desse ano, vive-se uma série de contradições políticas e ideológicas que tem conseqüências visíveis na vida da população. Por isso, é importante questionar em que medida o telejornalismo moçambicano tanto da rede pública quanto privada serve para estabelecer e sustentar relações de dominação nos contextos em que as notícias são produzidas, difundidas e recebidas? Qual a relação entre o discurso da televisão pública ou privada e o poder político?

Fairclough (2001, p. 94) afirma que "o discurso como prática ideológica constitui, naturaliza, mantém e transforma os significados do mundo em posições diversas nas relações de poder". Essa discussão sobre discurso e ideologia nos direciona a pensarmos em outro conceito, o da hegemonia. Para a compreensão da sua epistemologia, recorremos às bases teóricas de Laclau e Mouffe que se debruçaram sobre o contexto em que essa categoria emergiu no seio do marxismo.

Esses autores baseiam-se nas formulações de António Gramsci que, sem dúvida, foi o teórico que mais se debruçou sobre a noção de hegemonia em sua amplitude. Para Gramsci apud Gruppi (2000), hegemonia significa a capacidade de uma classe dominante ou aspirante ao domínio de construir consenso e/ ou obter a passividade da maioria da população, constituindo-se então em classe dirigente, com capacidade de direção intelectual e moral.

Hegemonia pode significar também ausência de totalidade, ou predomínio majoritário de um grupo, de uma classe sobre outra ou mesmo do Estado sobre o povo. Neste ensaio, consideramos relevante o significado de hegemonia enquanto predomínio político e ideológico de um partido sobre a maioria e que é transposto para os veículos de comunicação de massa. 
Na concepção de Laclau (1985, p. 07), os contextos em que o conceito de hegemonia surgiu traduziam uma crescente percepção de um vazio, na estrutura teórica do marxismo. "Surge na socialdemocracia russa como intervenção contingente para resolver uma crise ou colapso do suposto curso normal do desenvolvimento".

A partir de um processo, que os autores designaram desconstrução, Laclau e Mouffe desconstroem o marxismo, por meio da crítica da teoria marxista clássica para das suas bases criarem novas categorias, como a de hegemonia, com a finalidade de se pensar na possibilidade da criação de uma democracia radical.

Nesse processo, Laclau e Mouffe defendiam a tese de que não se tratava de um desvio em relação à origem, mas reconheciam que a obra de Marx era atingida e acreditavam que essa releitura da teoria marxista fosse uma alternativa viável para a compreensão de sua relação com o presente, além de sua historicidade, como uma forma de manter vivo o marxismo.

Do ponto de vista mais crítico, a releitura do marxismo original só tem sentido se se pautar pela busca da compreensão da especificidade do mundo contemporâneo. E um dos focos da ambigüidade do marxismo, detectado por Laclau (1985, p. 07), centra-se justamente no conceito de hegemonia, que na visão do autor, "não emerge para definir um novo tipo de relações sociais em sua identidade específica, mas para preencher uma lacuna das classes sociais desfavorecidas".

Para Laclau, a hegemonia dá-se no campo da ideologia e um discurso se torna hegemônico quando o seu autor consegue fazê-lo ouvido, repetido e aceito pelos demais. Na prática, para se fazer ouvir, o poder político moçambicano (o governo), serve-se da mídia, sobretudo, dos veículos públicos que são por ele controlados. Na semiótica greimasiana, tal ação pressupõe certas estratégias de manipulação (no sentido de persuasão), que um sujeito realiza intencionalmente para fazer o outro indivíduo desenvolver uma ação desejada pelo primeiro.

Essas asserções parecem encontrar apoio nas idéias de Mészarós (2004, p. 59) de que "a ideologia dominante do sistema social estabelecido se afirma fortemente em todos os níveis, do mais baixo ao mais refinado". Para Mészarós, "a ordem dominante precisa aplicar para si mesma critérios radicalmente diferentes dos aplicados àqueles que devem ser mantidos em sua posição subordinada".
Essa hierarquia ideológica, se é que se pode assim denominar, pode ser compreendida na argumentação de Chaui (1981, p. 93) quando explica que a ideologia consiste na transformação das idéias da classe dominante em idéias dominantes para a sociedade como um todo, de modo que a classe que domina no plano material (econômico, social e político) também domina no plano espiritual (das idéias).

Com base em Gramsci apud Laclau (1985), hegemonia significa a capacidade de uma classe dominante ou aspirante ao domínio de constituir o consenso e/ou obter a passividade da maioria da população, constituindo-se, assim, em classe dirigente, com capacidade de direção intelectual e moral. Portanto, na concepção de Laclau (1985, p.105), a hegemonia forma-se, compõe-se de, e articula dois "momentos": o primeiro é o do consenso, colocado na instância da sociedade civil. Esse cria a base do consentimento, ativo ou passivo, para o estabelecimento de certa ordem social; o segundo é o "domínio", na instância da sociedade política ou Estado.

Nessa linha de pensamento, vemos que o caso do telejornalismo da rede pública e privada de Moçambique pode ser analisado sob ponto de vista desses dois momentos. Até porque é importante frisar que ambos os momentos, o do consenso e o de domínio, acontecem ao mesmo tempo, ou seja, sobrepõem-se dialeticamente. É isso que se viveu em Moçambique e ainda tem repercussão na atualidade embora já tenham passado bons anos depois do abandono, mesmo que teoricamente, da ideologia marxista-leninista.

A partir dessa leitura, é possível compreender a tese de Rodrigues (1990, p. 161) quando analisa as relações entre os meios de comunicação e o poder político em países democráticos. Para Rodrigues, os órgãos de informação tornaram-se, nas democracias, cada vez menos claramente meios de informação, de proposta de projetos de sociedade, de programas políticos, e cada vez mais obviamente um campo social de encenação pública de imagens de marca que emprestam aos homens políticos, em função da sua própria estratégia de diversão e de sedução.

A visão de Rodrigues (1990, p. 161) de que “a lógica do poder, ao contrário da lógica da informação, não é função de transparência, mas do segredo, que detém o poder aquele que for detentor do segredo, ao passo que partilhar a informação não é deter, mas disseminar o poder" tem tudo a ver 
com as instâncias de poder que atuam em Moçambique. Suas atuações, muitas vezes, pautamse pelo segredo e pelo silêncio no tocante à divulgação de informações que seriam relevantes para o conhecimento da população, em se tratando de uma democracia consagrada pela constituição.

Os resultados dessas atuações são visíveis. A falta de independência da televisão pública se agrava ainda pelo fato de a direção ser indicada pelo governo e não por eleições abertas dentro da própria instituição. Aliás, essa indicação também é prevista pela lei de imprensa, cujo artigo 9 refere que "os diretores das empresas ou instituições do setor público são designados pelo governo".

Nessas condições se apresentam inúmeros desafios para os profissionais da comunicação que trabalham encurralados sob os auspícios, tanto do poder político quanto econômico, que lideram em Moçambique, pois, a rigor, numa verdadeira democracia, as pessoas deveriam usufruir o direito de se expressarem sem passar por qualquer tipo de constrangimentos políticos.

\section{Considerações finais}

Com esse panorama, já se pode vislumbrar o dilema que os profissionais da comunicação atravessam. De um lado, reconhecem as exigências da ética profissional e do seu compromisso com o público telespectador e, de outro, a permanente pressão e controle sutil do governo sobre as atuações dos jornalistas. Difícil mesmo é servir a dois senhores ao mesmo tempo. Quem perde nessa disputa é o público que deveria usufruir seu direito à informação e outras questões inerentes ao bom uso dos meios de comunicação como, por exemplo, para a educação escolar ou cívica.

Esses e outros fatores conflitantes atingem diretamente o funcionamento da emissora pública. Sua qualidade de programação é fraca, uma vez que depende do orçamento do Estado, que nem sempre é suficiente para arcar com todos os encargos financeiros.

Quanto a STV, o discurso muda de rumo, pois a emissora busca outros fins que têm mais a ver com a obtenção de lucros e de hegemonia na audiência. Vale lembrar que a STV pertence a alguns empresários moçambicanos que atuam na área de telecomunicações e, obviamente, seus objetivos passam pela ampliação do mercado de bens simbólicos.
É por isso que o estudo do telejornalismo da rede pública e privada de Moçambique não pode prescindir de uma análise mais aprofundada das relações entre esse formato televisual com as instâncias de poder político do país e até mesmo dentro dos veículos de comunicação de massa, pois, a nosso ver, há sempre disputas entre as duas instituições: televisão e governo.

Face aos novos imperativos da atualidade, o quadro político e ideológico que se vive em Moçambique parece constituir-se em um condicionamento para o desempenho do Jornal Nacional e Jornal da Noite. A televisão pública parece pretender continuar a legitimar o discurso do governo, mostrando-se em contrapartida como neutra, imparcial, objetiva enquanto a emissora privada se mostra cada vez mais distante dessa postura, talvez por conveniência.

\section{Referências}

BECKER, Beatriz. A linguagem do telejornal: um estudo da cobertura dos 500 anos do Descobrimento do Brasil. Rio de Janeiro: E-Papers, 2005.

BOLAÑO, Cesar Ricardo Siqueira. Mercado brasileiro de televisão. São Paulo: EDUC, 2004.

CHAMBOTE, Raúl Meneses. O exercício do poder político à luz da constituição nos estados em África: o caso de Moçambique. 2006. 65 f. Monografia (Licenciatura em Relações Internacionais) - O Instituto Superior de Relações Internacionais, Maputo, 2006.

CHAUÍ, Marilena. O que é ideologia. São Paulo: Brasiliense, 1981.

FAIRCLOUGH, Norman. Discurso e mudança social. Brasília: UNB, 2001.

GREIMAS, Algirdas Julien; COURTÉS, Joseph. Dicionário de semiótica. Tradução de Alceu Dias Lima et al. São Paulo: Cultrex, 1979.

GRUPPI, Luciano. O conceito de hegemonia em Gramsci. 4. ed. Rio de Janeiro: Graal, 2000.

LACLAU, Ernesto; MOUFFE, Chantal. Hegemony and socialist strategy: towards a radical democratic politics. London: Verso, 1985

LIPOVETSKY, Gilles. O império do efêmero: a moda e seu destino nas sociedades modernas. São Paulo: Companhia da Letras, 2005. 
MACHADO, Arlindo. A televisão levada a sério. São Paulo: Senac, 2003.

MAZULA, Brazão. Educação, cultura e ideologia em Moçambique: 1975-1985. Maputo: Afrontamento, 1995.

MELO, José Marques. Comunicação, opinião e desenvolvimento. Petrópolis: Vozes, 1979.

MÉSZAROS, Istvan. O poder da ideologia. São Paulo: Boitempo, 2005.

MIGUEL, João. Televisão e espaço público em Moçambique: o público e o privado. 2003. 112 f. Dissertação (Mestrado em Ciências da Comunicação) - Universidade do Vale do Rio dos Sinos, São Leopoldo, 2003.

OLIVEIRA, Ana Cláudia. Estética del telegiornale: identità di testata e stili comunicativi. Revista de Estudos de Comunicação e Educação, São Paulo, v. 2, n. 3, 1998.

RODRIGUES, Adriano Duarte. Estratégias da comunicação. Lisboa: Presença, 1990.

SAÚTE, Nelson. O arremedo do regime: breve análise comparativa de títulos de primeira página do notícias. In: RIBEIRO, Fátima; SOPA, António. 140 anos de imprensa em Moçambique. Maputo: AMOLP, 1996. p. 153-169.
TOMÁS, Celestino Vaz. Visão crítica dos media moçambicanos. Moçambique: Maria Cremilda Massingue, 2005. Relatório Anual do MISA. Disponível em: <www.misa.org.mz>. Acesso em: 22 jan. 2007.

THOMPSON, John. Ideologia e cultura moderna: teoria social crítica na era dos meios de comunicação de massa. Petrópolis: Vozes, 1998.

TRAQUINA, Nelson. O estudo do jornalismo no Século XX. São Leopoldo, Rio Grande do Sul: Unisinos, 2003.

TRIVINHO, Eugênio. O mal-estar da teoria: a condição da crítica na sociedade tecnológica atual. Rio de Janeiro: Quartet, 2001.

VASCONCELOS, Leite Algumas reflexões sobre a imprensa pós-independência. In: RIBEIRO, Fátima; SOPA, António. 140 anos de imprensa em Moçambique. Maputo: AMOLP, 1996. p. 139-143.

WOLF, Mauro. Teorias da comunicação de massa. São Paulo: Martins Fontes, 2003.

Recebido em: 08/02/2007

Received in: 02/08/2007

Aceito em: 16/04/2007

Accepted in: 04/16/2007 